\title{
Detection of the Possible Buried Archeological Targets Using the Geophysical Methods of Ground Penetrating Radar (GPR) and Self Potential (SP), Kom Ombo Temple, Aswan Governorate, Egypt
}

\author{
Salem B. A. Yousef, Mohamed H. M. Yousef, Hussein F. Abd-Elsalam, Mohamed A. M. Shaheen \\ Nuclear Materials Authority, Cairo, Egypt \\ Email: mamshaheen2002@yahoo.com
}

How to cite this paper: Yousef, S.B.A., Yousef, M.H.M., Abd-Elsalam, H.F. and Shaheen, M.A.M. (2020) Detection of the Possible Buried Archeological Targets Using the Geophysical Methods of Ground Penetrating Radar (GPR) and Self Potential (SP), Kom Ombo Temple, Aswan Governorate, Egypt. Geomaterials, 10, 105-117. https://doi.org/10.4236/gm.2020.104007

Received: August 7, 2020

Accepted: September 12, 2020

Published: September 15, 2020

Copyright $\odot 2020$ by author(s) and Scientific Research Publishing Inc. This work is licensed under the Creative Commons Attribution International License (CC BY 4.0).

http://creativecommons.org/licenses/by/4.0/

\section{(c) (i) Open Access}

\begin{abstract}
Kom Ombo temple is one of temples which were belted over high plateau close to the River Nile, near to Aswan in Egypt in the Greek-Roman period. The expected archaeological remains in the selected area are the hidden tunnels of the mummified crocodiles. The aim of the present work is to detect any of these tunnels by the application of the (GPR) and (SP) methods. The interpretation of the $10 \mathrm{GPR}$ profiles revealed some locations of possible hidden tunnels. These locations show different contrasts and high amplitudes of the reflected signals, compared to the enclosing soil; also the scattering of the signals is higher than the bed layer in these locations, which may reveal the possible buried mummified crocodile tunnels in the study area. The depths of the possible targets range from $2.0 \mathrm{~m}$ to $2.5 \mathrm{~m}$. The SP electric map shows that the study area possesses a range of about $135 \mathrm{mV}$ of the potential differences between the measured stations. The positive response of the SP data is mainly concentrated at the central part of the study area. The relatively weak, negative SP anomalies may be related to moisture in the soil. The positive SP anomalies on the SP electric map display possible significant correlation between them and the inferred tunnel locations from the GPR data. The calculated depths from the SP profiles show significant agreement with that estimated from GPR data depths, which indicate that the SP electric method can be used as a successful tool in detecting buried archaeological remains in support of GPR.
\end{abstract}

\section{Keywords}

Ground Penetrating Radar, Self-Potential, Kom Ombo Temple, Aswan, Egypt 


\section{Introduction}

Kom Ombo city is located at about $40 \mathrm{~km}$ to the north of Aswan city, in adjacent to the River Nile (Figure 1). Kom Ombo temple is located to the south of Kom Ombo city at the intersection of latitudes $24^{\circ} 27^{\prime} 8^{\prime \prime} \mathrm{N}$ and longitudes $32^{\circ} 55^{\prime} 42^{\prime \prime} \mathrm{E}$ (Figure 1 and Figure 2).

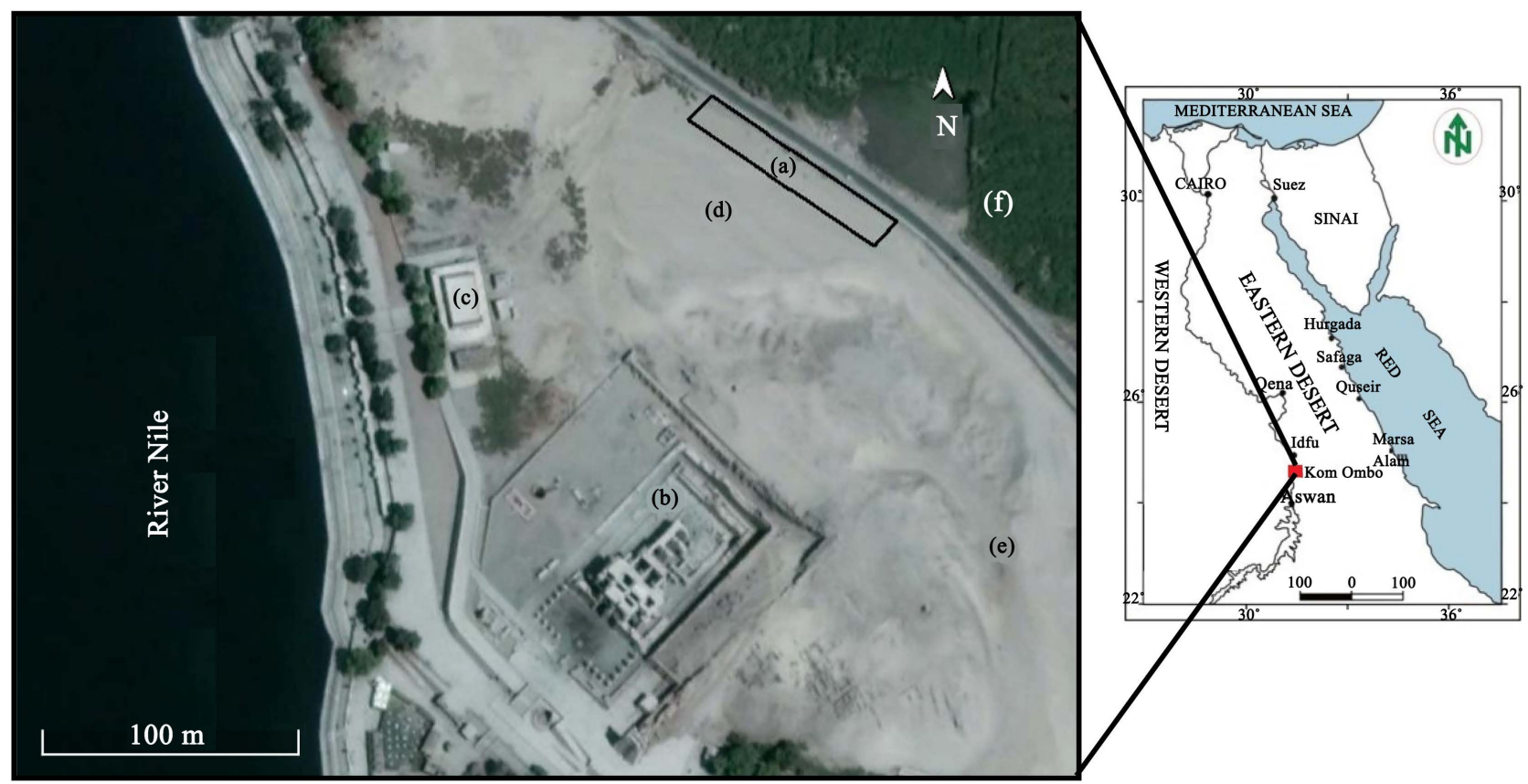

Figure 1. Location map of the study area, (a) Study area; (b) Kom Ombo temple; (c) Mummified crocodiles museum; (d) Unexcavated area; (e) Excavated area and (f) Cultivated area, Kom Ombo city, Aswan Governorate, Egypt.

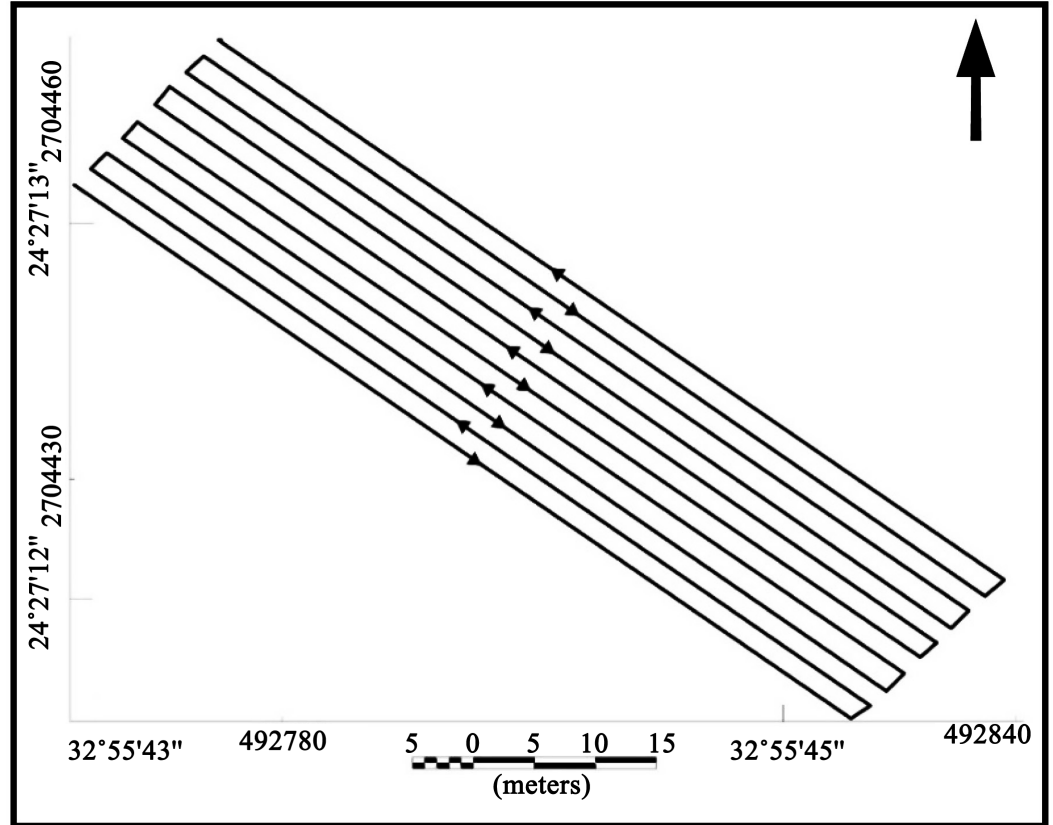

Figure 2. Base map of the selected locations of the GPR profiles and their directions, Kom Ombo temple area, Aswan governorate, Egypt. 
Kom Ombo temple is one of the Greek-Roman temples which were built over high plateau close to the River Nile in Egypt in the Greek-Roman period. The temple was dedicated for worshiping the God Sobek, the crocodile headed God. In that period, they mummified the crocodiles and hid them in tunnels under the temples. Many excavations were carried out to discover the archaeological remains in the temple. In some of these excavations, they discovered some mummified crocodiles, still found in the museum inside the temple. These tunnels were discovered in different depths. Other tunnels are still buried under the temple [1].

The expected archaeological remains in the selected area are the hidden tunnels of the mummified crocodiles, depending to the reports of the previous excavations which were conducted close to the study area [2]. This area was selected because it was not excavated till now.

The sediments succession in the study area is belong to the Nile valley succession sediments of the late Cretaceous to early Eocene which is dry mud and sandy mud overlying the wet sand layer [3].

The aim of the present work is to detect any possible buried tunnel of the mummified crocodiles through the application of GPR and SP methods.

According to the previous excavations, the bed layer sequence in the selected area is from top to bottom: dry mud, sandy mud and wet sand. All the discovered mummified crocodiles were buried in wooden coffins.

\section{Ground Penetrating Radar (GPR) Survey}

\subsection{GPR Basic Concept}

Ground-penetrating Radar (GPR) is a near-surface geophysical technique that allows archaeologists to discover and map buried archaeological features for landscape analysis in ways not possible using traditional field methods. The method consist of measuring the elapsed time between when pulses of radar energy are transmitted from a surface antenna, reflected from buried discontinuities, and then received back at the surface. When the distribution and orientation of those subsurface reflections can be related to certain aspects of archaeological sites such as the presence of architecture, use areas or other associated cultural features, high definition three-dimensional maps and images of buried archaeological remains can be produced [4] [5] [6].

Most of the possible archaeological targets are buried in clay soil. It is important to understand that the depth of penetration is highly dependent on the clay content of the medium, with clay significantly attenuating electromagnetic waves and limiting the investigation depth [7].

\subsection{The GPR Instrument Used in Present Study}

In the present study, MALA GPR system was used connected to $100 \mathrm{MHz}$ antenna (Figure 3). It provides a detailed look at what's beneath the surface. The system offers leading-edge GPR technology, with full digital control of all setup parameters and multi-channel color display. 


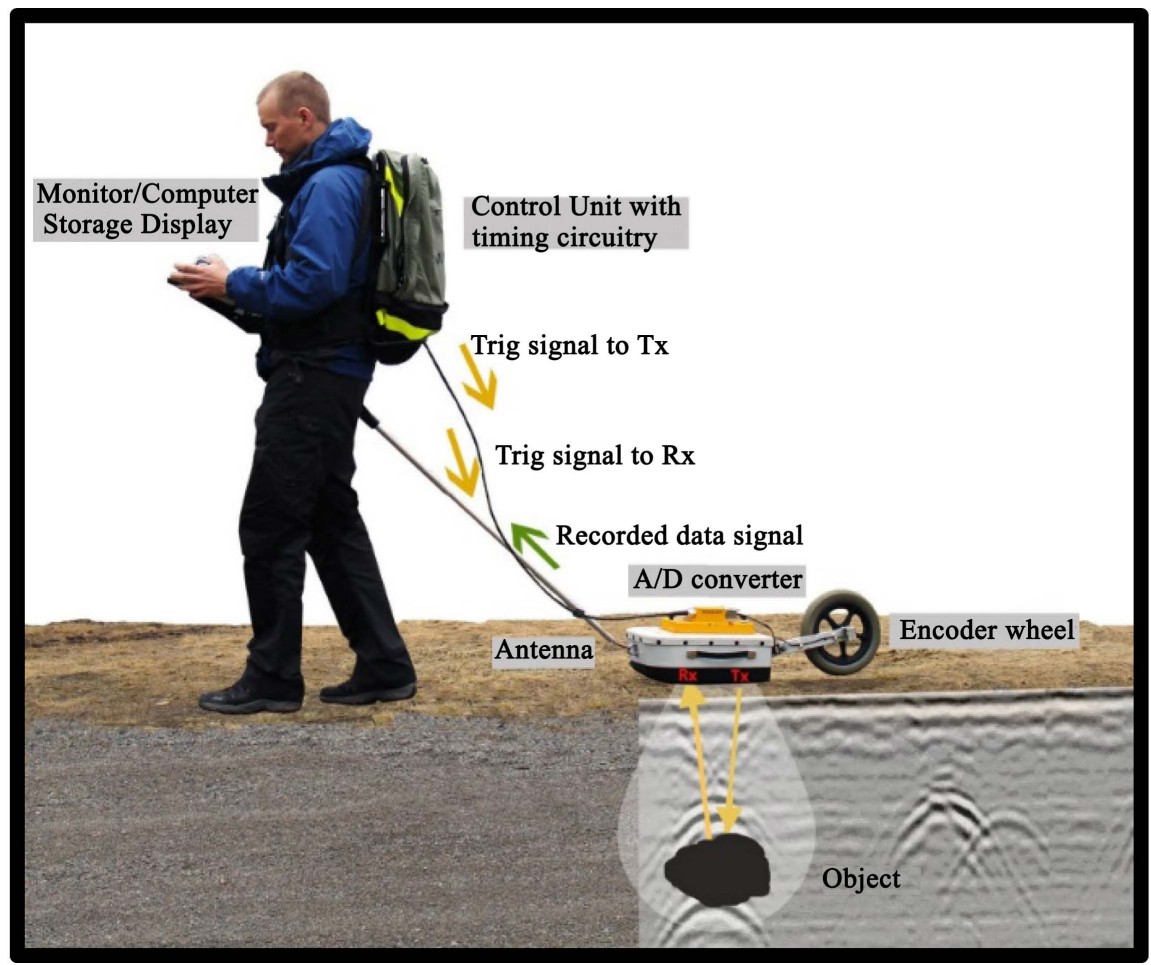

Figure 3. The used GPR MALA system on the selected area.

\subsection{GPR Data Collection and Processing}

GPR data acquisitions are very similar to the method used in seismic reflection. However, GPR has much higher resolution and it is sensitive to changes in electromagnetic rather than caustic properties. GPR reflections are caused by electromagnetic waves encountering media that have different electrical properties namely; boundaries consisting dielectric constant contrasts. Reflection is approximately proportional to the difference of the dielectric constants at the boundary [8].

In the selected area, $10 \mathrm{GPR}$ profiles were conducted with a line separation of $1 \mathrm{~m}$, using antenna of $100 \mathrm{MHz}$. The GPR profiles are processed using the software program (Reflex W, 2D/3D). The applied parameters for filtering the raw data were as following; Static correction, cross-correlation, deconvolution, Fk migration, back ground removal and remove range.

\subsection{GPR Data Results and Analysis}

An analysis of the spatial distribution of the amplitudes of the reflected waves is important because it is an indicator of the subsurface changes in lithology and other physical properties. The higher the contrasting velocity at a buried object, the greater the amplitude of the reflected waves. The amplitude changes can be related to the important buried features and stratigraphy.

The location of the higher and lower amplitudes at specific depths can be used to detect the possible buried objects and the surrounding soil. Areas of low amplitude waves indicate uniform matrix materials or soil, while those of high am- 
plitude waves denote areas of high subsurface contrast, such as buried archaeological features [9] (Figure 4).

The objective of this study was to allocate the possible buried mummified crocodiles under the ground in the study area. Interpreting the processed GPR data depend on observing the scattering, the amplitude and the high contrast of the reflected waves from the possible targets related to the soil surrounded. The first group of the processed GPR profile data: P1, P2, P3, and P4 (Figure 5). The blue polygons reveal the locations of the possible hidden tunnels, depending on the strong wave reflections related to the surrounding soil. These locations show different contrasts and high amplitudes of the reflected signals compared to the soil. Also the scattering of the signals is higher than the bed layer in these locations, which may reveals the possible buried mummified crocodile tunnels in the study area. The depths of the possible targets range from $2.0 \mathrm{~m}$ to $2.5 \mathrm{~m}$.

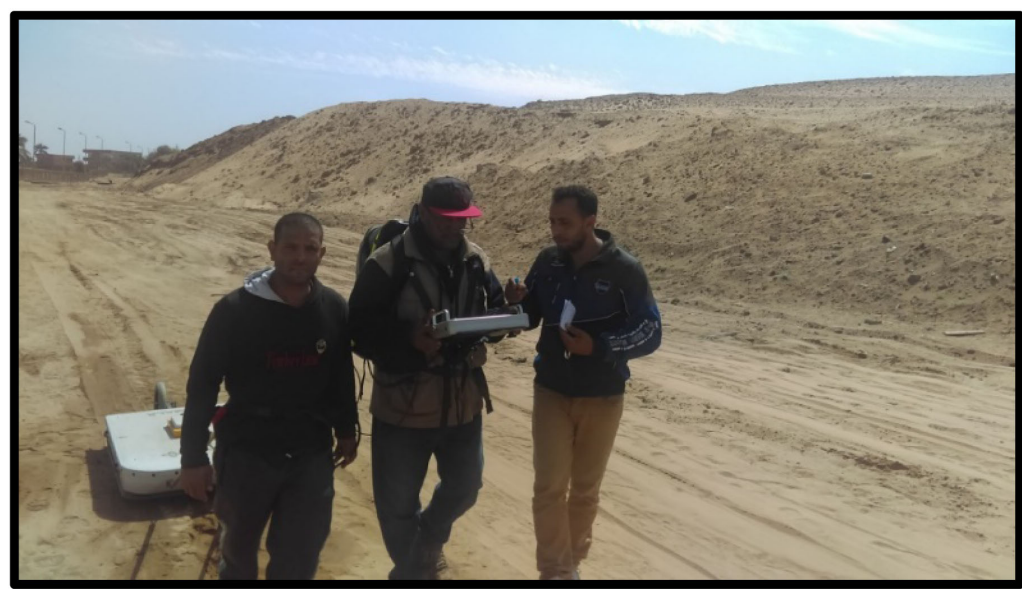

Figure 4. Photograph showing the data collection on the study area.

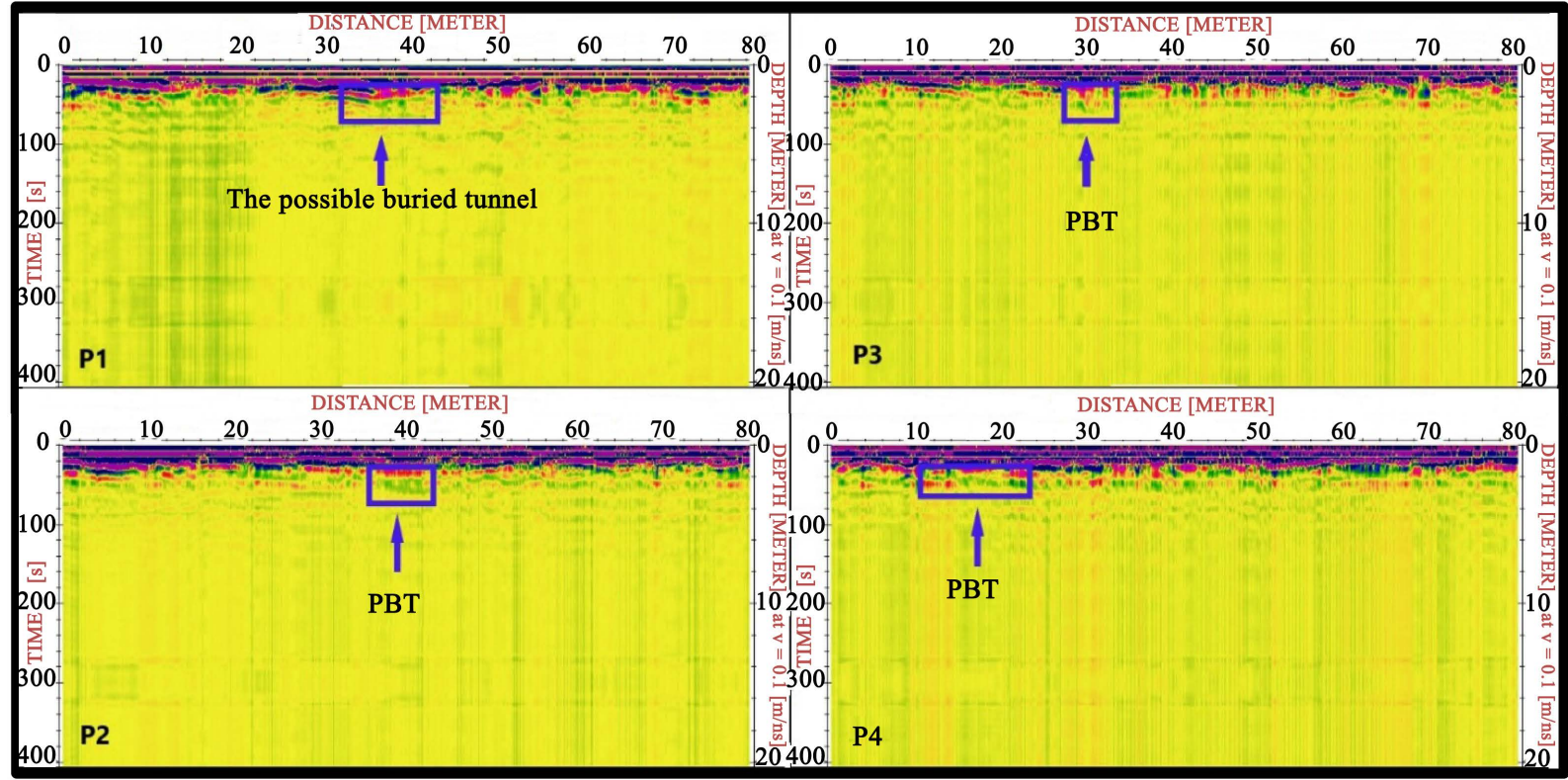

Figure 5. The interpreted GPR profiles P1, P2, P3, and P4. 
For the second group which includes the GPR profiles P5, P6, P7 and P8 (Figure 6). On P5, there is no clear variation in all the reflected waves of the subsurface features, so that there are no clear possible targets in this profile. In case of P6, P7 and P8, the marked locations from the scattering and the high amplitude of the reflected signals, may reveal the possible buried tunnels in these locations at depth range from $2.0 \mathrm{~m}$ to $2.5 \mathrm{~m}$.

Visual inspection to the reflected signals of the subsurface materials for the last group, which includes the two profiles (P9 and P10) as shown on Figure (7), showed that, there are no enough and clear variations from the start to the end of these profiles. All the contrasts and the amplitudes of the reflected waves are relatively similar and there are no discontinuities in these signals, so there are no clear possible targets along these profiles (Figure 7).

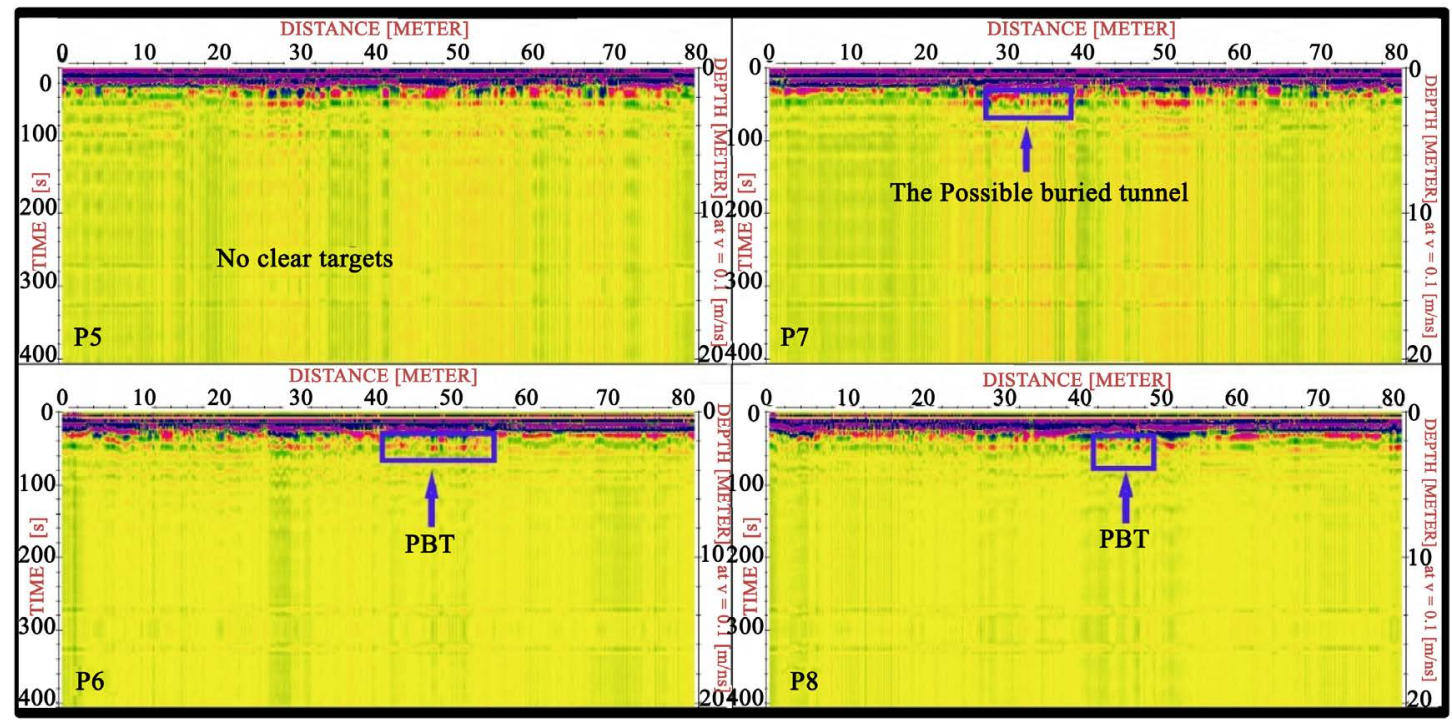

Figure 6. The interpreted GPR profiles P5, P6, P7, and P8.

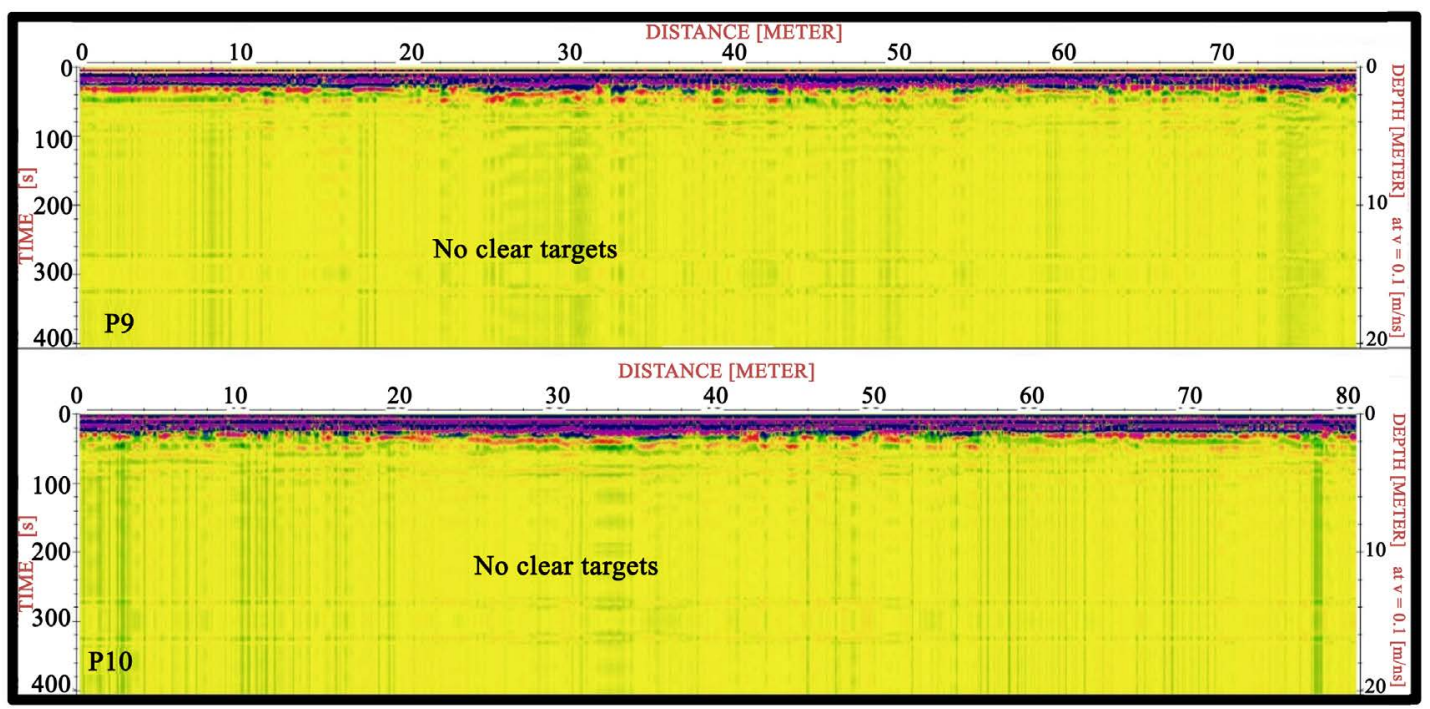

Figure 7. The interpreted GPR profiles P9, and P10. 


\subsection{D Analyses of the GPR Data}

Three-dimensional interpretations of the ground-penetrating radar (GPR) data were applied to identify burials and other cultural features. The recent development of sophisticated software has enabled signal enhancement and improved pattern recognition on radar records [9].

Time slicing was performed for the GPR results to illustrate the presence of possible buried tunnels in the study area in a 3D form as shown in Figure 8 and Figure 9. From the interpreted GPR profiles, the possible targets were noticed at depths ranging from $2.0 \mathrm{~m}$ to $3 \mathrm{~m}$, equal to $40 \mathrm{~ns}$. The time slices revealed that the possible targets are located at the same depths, which confirm the locations of the relatively high reflected signals caused by the possible buried targets. The purpose from getting these slices and illustrating the collected GPR profiles is to confirm the correct depths of the strong reflected signals related to the low and medium reflections of the surrounding soil.

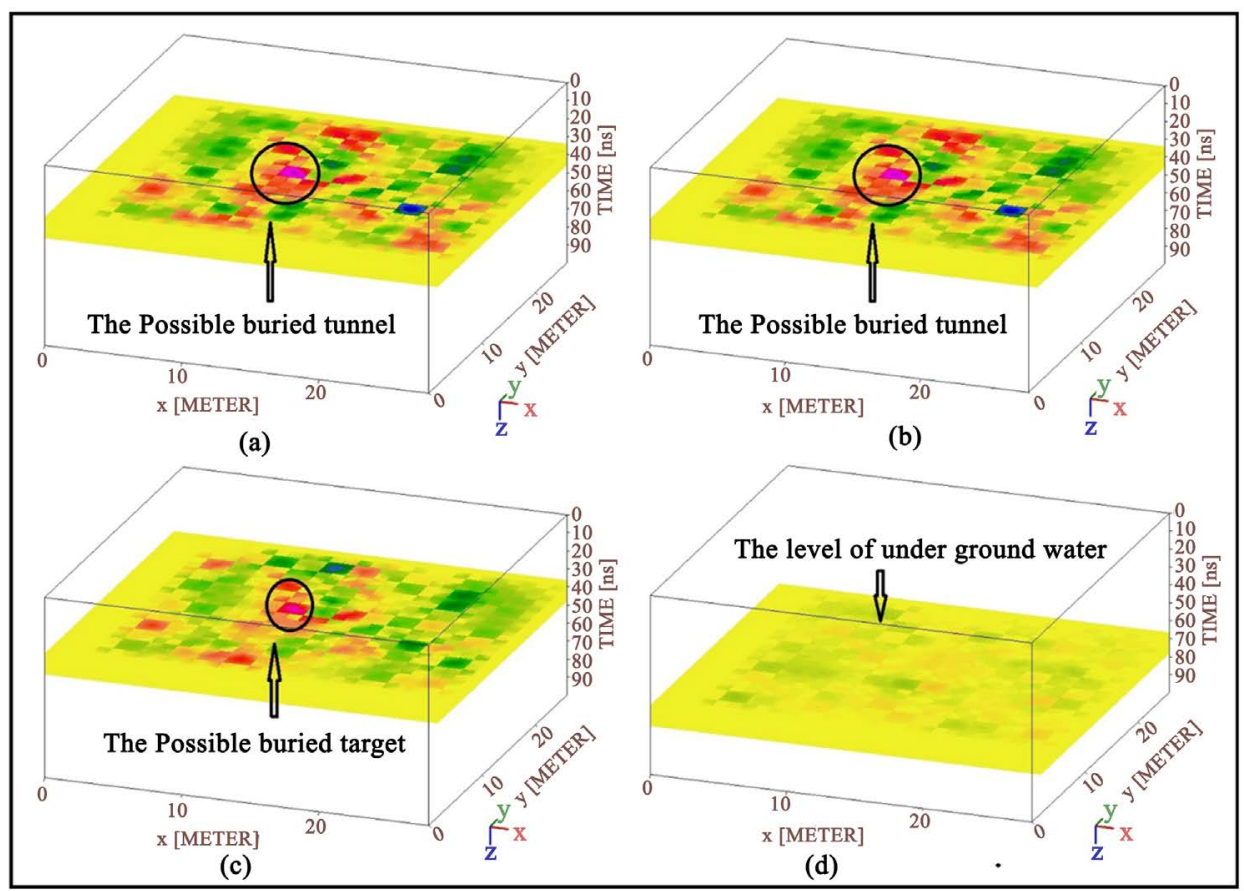

Figure 8. Time slices of the processed GPR profile collections.

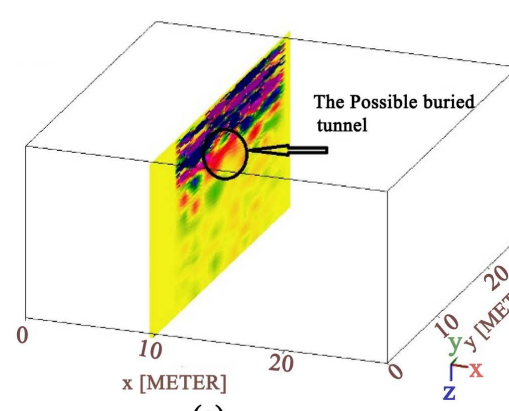

(a)

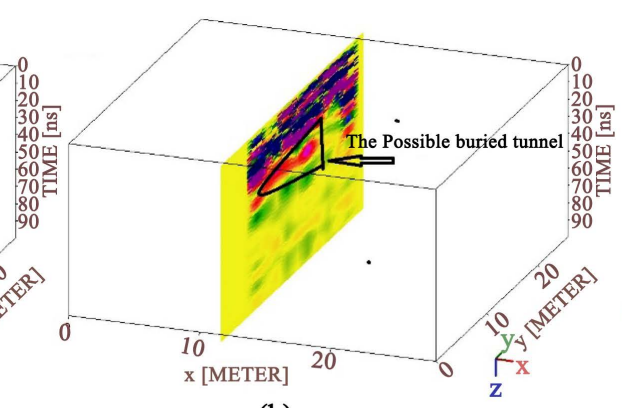

(b)

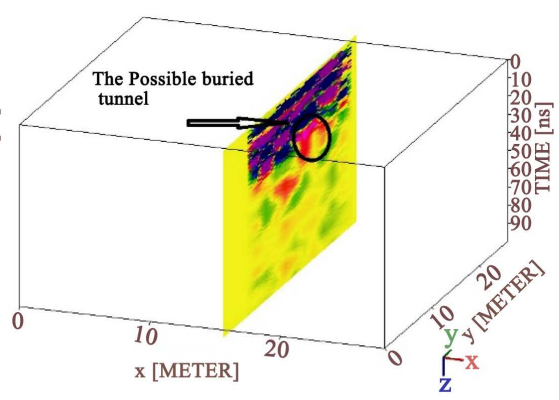

(c)

Figure 9. X-cut slices of the processed GPR profile collections. 


\section{Self-Potential (SP) Survey}

\subsection{Basic Concept of Self-Potential Method}

The SP method has been used in different geological and engineering problems, such as: mining exploration [10] [11], hydrogeology [12] [13], geothermal [14] [15] [16], and archaeological prospection [17] [18] [19].

The SP data is generated from the measurements of naturally occurring electric potentials across two electrodes placed on the earth's surface and the potentials measured during these surveys are small, generally less than 100 millivolts, and may be positive or negative to locate anomalies of interest [20]. Sources of SP effects are varied and include oxidation of sulphide mineral deposits, bioelectric activity in vegetation, varying electrolytic concentration in water, fluid motion through a porous medium called streaming potentials [21].

The background potentials are the main reason for anomalies in geothermal, hydrogeology and engineering geology investigations, and in archaeological prospection. Background potentials include those caused by telluric currents, cultural activity and bioelectricity. There are two types of time variable potentials: electrokinetic and electrochemical. Electrokinetic potential occurs because of an electrolyte flowing through a capillary or a porous medium, and this potential is called streaming, electromechanical or electrofiltration potential. Electrokinetic phenomena are the main generator of potential anomalies in archaeological areas [17] [18]. The first of the known SP applications in archaeological prospection was carried out by Wynn and Sherwood (1984) at different archaeological sites in USA (Fort Washington, Piscataway and Harpers Ferry sites). According to Wynn and Sherwood, Variations in soil porosity and clay content caused by digging and back filling should give rise to variations in the voltage measured by an SP survey. Buried stone foundations should also affect the measured SP; a solid, relatively non-porous body should interrupt the vertical water flow and give rise to an SP voltage on the ground positive above it. A loose stone assemblage, with many cracks and a relatively larger downward movement of water might, conversely, give rise to an SP negative on the ground above it, if the same streaming potential is going on in the overlying soil. Electrochemical potentials occurring in diffusion and Nernst (or shale) potential forms can be taken as two separate situations. The main causes of diffusion potentials are differing on concentrations within the groundwater solution and their varying mobility. These potentials generate anomalies of a few tenths of a millivolt.

\subsection{SP Data Interpretation}

In this study, the SP method is applied to measure the response of the possible archaeological targets and integrate these results with the GPR data. The main idea of using the SP method in this study is the possibility that there are spaces inside the tunnels, as well as the presence of different materials inside the tunnels that may be different in composition from the dusty environment around 
them, which can leads to the presence of a clear difference of potential around it, which enable to measure these differences in voltage and identify the zones of the sub-surface tunnels.

Ten SP profiles were carried out over the GPR profiles with station separation $1 \mathrm{~m}$. The SP survey was applied with the GPR technique to confirm the response of the GPR method in detecting the buried targets in the archaeological prospecting.

The SP electric filled-colour map (Figure 10) shows that the study area possesses a range of about $135 \mathrm{mV}$ of the potential differences between the measured stations. The positive response of the SP data is mainly concentrated at the central part of the study area. In addition, a number of relatively weak, negative SP anomalies are distributed through the study area. These anomalies may be related to moisture in the soil. A close correspondence exists between the positive SP anomalies on the SP map display a significant correlation between the SP anomalies and the deduced tunnel locations from the GPR data (Figure 11).

These positive values can be due to two reasons; the first reason may be the woody material that constitutes coffins, which is less in the humidity than the soil surrounding it, and therefore showed a higher effect. The second reason may be due to the presence of voids in the coffins filled with air. The presence of these voids reduces the electrokinetic process and gives rise to an SP voltage positive above it.

The quantitative interpretation of the SP data depends usually on the transformation of the SP anomalies to a physical model of simple geometric shape. The model parameters include shape, depth and polarization angle that use

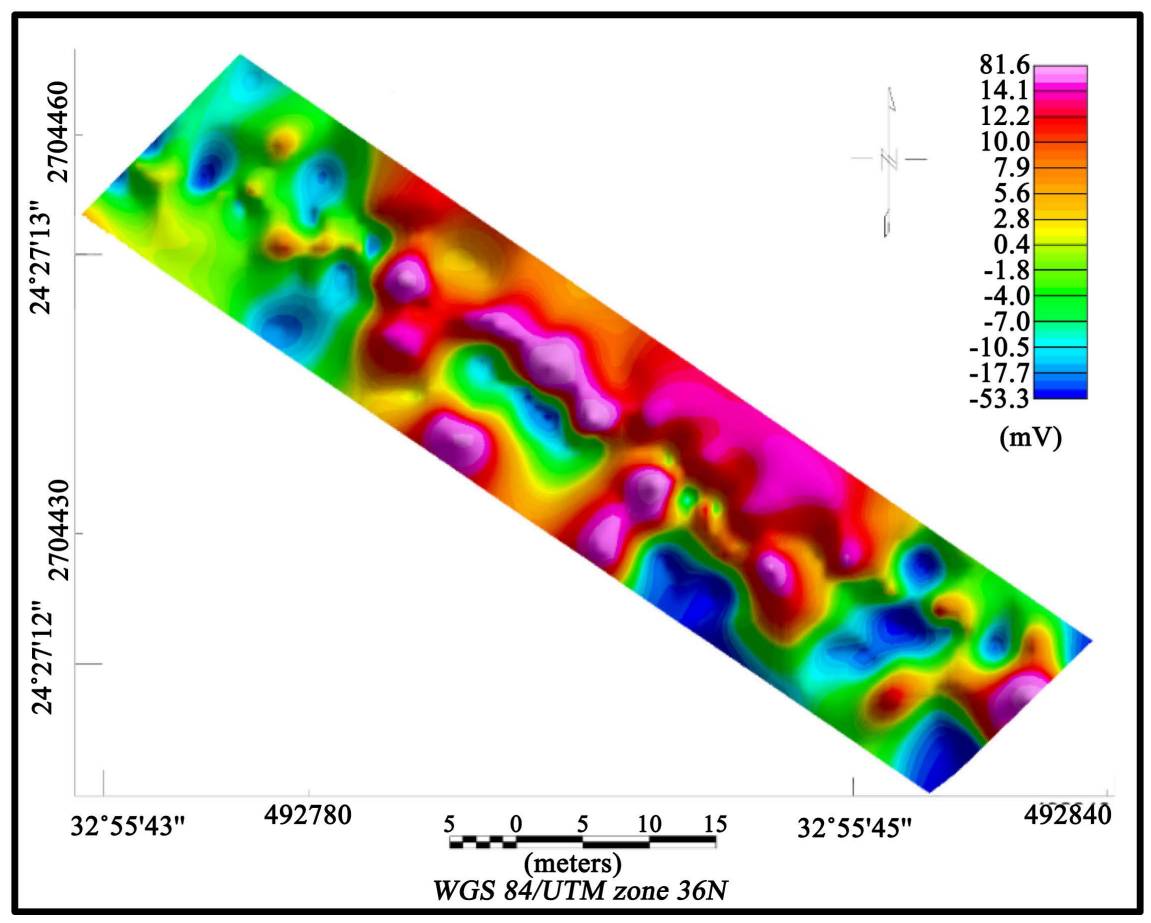

Figure 10. Self-potential (SP) filled colour map of the study area. 


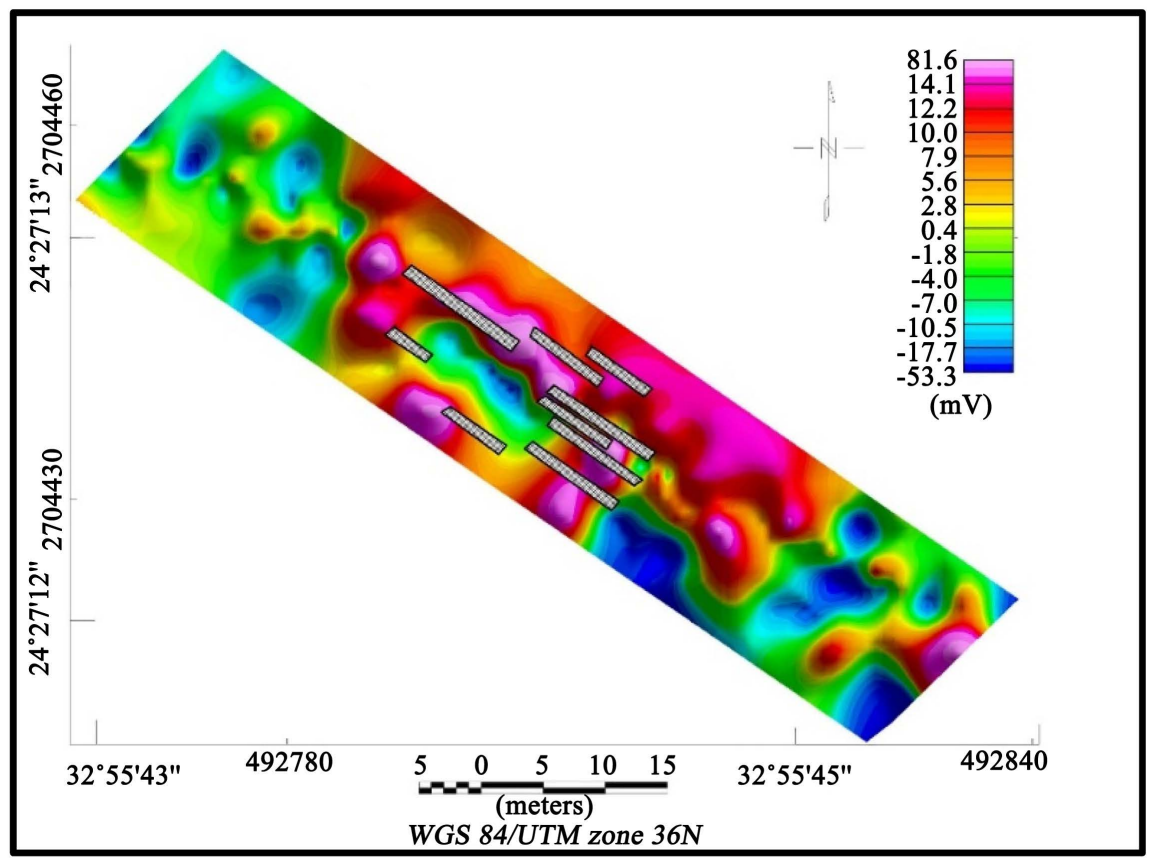

Figure 11. Self-potential (SP) filled colour map showing the locations of the inferred tunnel locations.

several graphical methods. In the present study, two SP anomaly profiles, representing two anomalies, were selected for the quantitative interpretations (Figure 12 and Figure 13). The depths of the source anomalies were evaluated using the method of characteristic curves [22] where the field profiles can be easily and accurately interpreted in a very short time. Figure 12 and Figure 13 illustrate the possible buried tunnels as interpreted from GPR data and their corresponding SP anomalies. As shown on the two figures, there are obvious changes in the voltages related to the buried objects. The calculated depths for these two anomalies were $2.8 \mathrm{~m}$ and $2.3 \mathrm{~m}$, respectively.

Comparison of these calculated depths with GPR measured depths shows very well agreement, which indicate that the SP method can be used as a successful tool in detecting buried tunnels with GPR.

\section{Conclusions}

The aim of the present work is to recognize and detect the possible buried tunnels of the mummified crocodiles by the application of the GPR and SP methods. The expected archaeological remains in the study area are the hidden tunnels of the mummified crocodiles, depending to the reports of the previous excavations which were done close to the study area. This area was selected, because it is not excavated till now.

10 GPR profiles were conducted with a length of $80 \mathrm{~m}$ each and line separation of $1.0 \mathrm{~m}$, using antenna of $100 \mathrm{MHz}$. The interpretation of GPR profiles from P1 to P10, reveals the locations of the possible hidden tunnels, depending on the strongly wave reflections related to the surrounding soil. These locations 


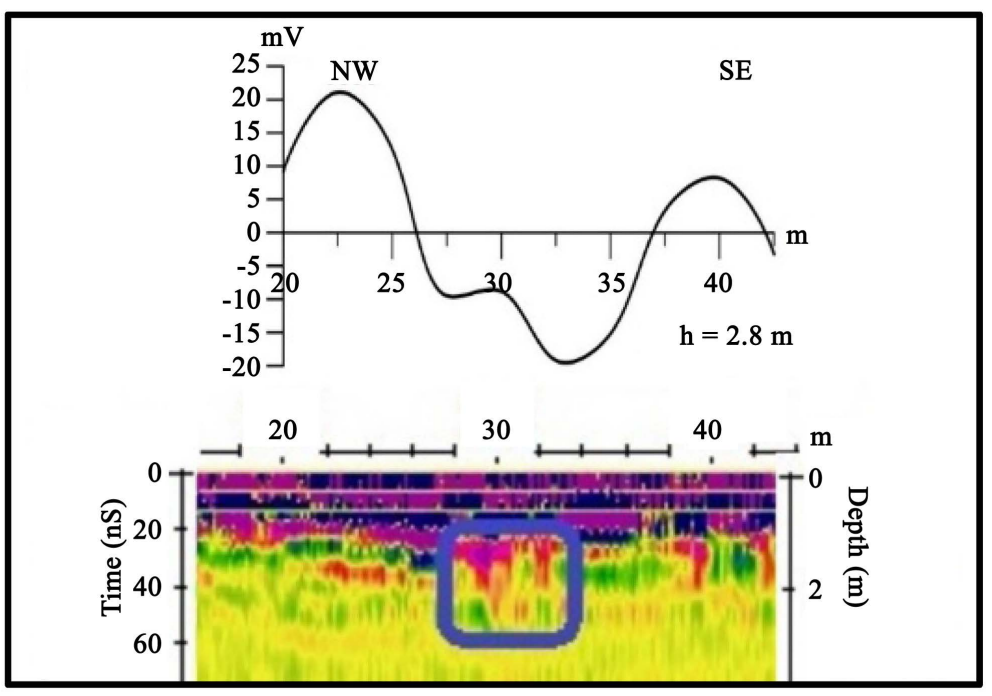

Figure 12. Integration of GPR profile (P3) with the SP line showing possible inferred tunnel.

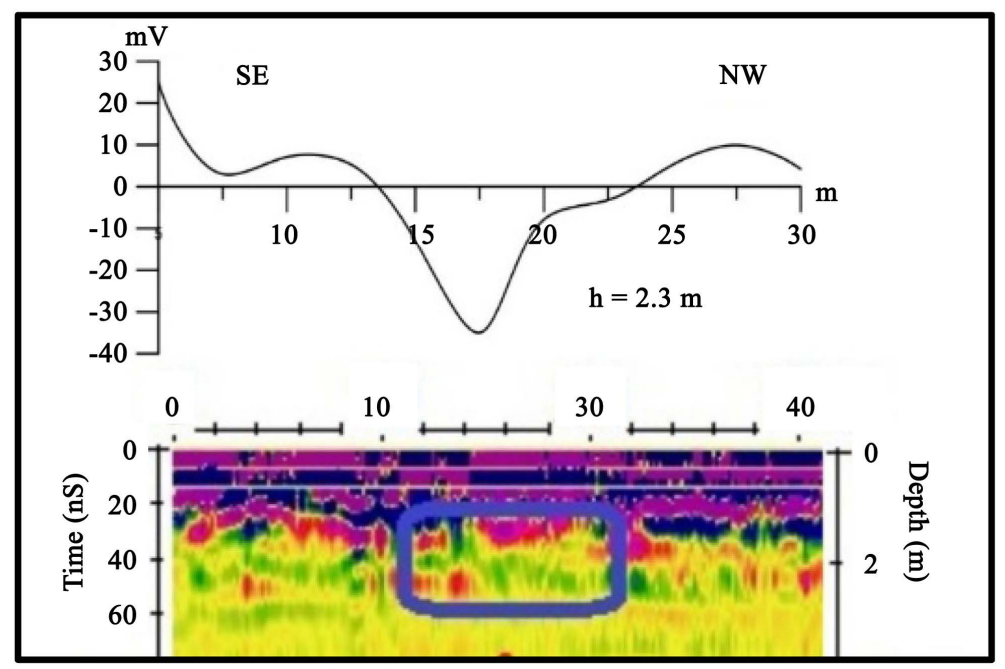

Figure 13. Integration of GPR profile (P4) with the SP line showing possible inferred tunnel.

show different contrasts and high amplitudes of the reflected signals, compared to the soil. Also the scattering of the signals is higher than the bed layer in these locations, which may reveals the possible buried mummified crocodile tunnels in the study area. The depths of the possible targets range from 2 to $2.5 \mathrm{~m}$.

The SP electric map shows that the study area possesses a range of about 135 $\mathrm{mV}$ of the potential differences between the measured stations. The positive responses of the SP data are mainly concentrated at the central part of the study area. The relatively weak, negative SP anomalies may be related to moisture in the soil. A close correspondence exists between the positive SP anomalies on the SP map, which may display a significant correlation between the SP anomalies and the inferred tunnel locations from the GPR data. The positive values may be due to two reasons: 1) the woody material that constitutes coffins, which is less 
in the humidity than the surrounding soil, and therefore shows a higher effect. 2) The presence of voids in the coffins filled with air. The presence of these voids reduces the electrokinetic process and gives rise to a positive SP voltage above it.

The quantitative interpretation of the SP data revealed that the calculated depths for the two anomalies were $2.8 \mathrm{~m}$ and $2.3 \mathrm{~m}$, respectively.

Comparison of the calculated SP depths with that of the GPR depths shows a very well agreement between both, which indicate that the SP method can be used as a successful tool in detecting buried archaeological remains with GPR. It is recommended to use $2 \mathrm{D}$ resistivity method, to ensure the accuracy of the results obtained in this study.

\section{Conflicts of Interest}

The authors declare no conflicts of interest regarding the publication of this paper.

\section{References}

[1] Rosalie, D. (1993) Discovering Ancient Egyptology. Facts on File, New York, 99.

[2] The Egyptian Antiquities Mission (2018) Internal Report of the Egyptian Antiquities Mission for the Excavations in Kom Ombo Temple.

[3] Said, R. (1981) The Geological Evolution of the River Nile. Springer Verlag, New York, 151 p. https://doi.org/10.1007/978-1-4612-5841-4

[4] Conyers, L.B. (2004) Ground-Penetrating Radar for Archaeology. Alta Mira Press, Walnut Creek, 203 p.

[5] Chris, G. and Gater, J. (2003) Revealing the Buried Past: Geophysics for Archaeologists. Tempus, Stroud, Gloucestershire.

[6] Daniels, D.J. (1996) Surface-Penetrating Radar. The Institution of Electrical Engineering, London.

[7] Bristow, C.S. (2013) Ground Penetrating Radar. In: Shroder, J.F., Ed., Treatise on Geomorphology, Academic Press, San Diego, 183-194. https://doi.org/10.1016/B978-0-12-374739-6.00383-3

[8] Sato, M. and Kim, J.-H. (2001) RADPRO/GPR V.3.0 User's Guide.

[9] Conyers, L.B. and Goodman, D. (1997) Ground-Penetrating Radar: An Introduction for Archaeologists. AltaMira Press, Walnut.

[10] Sato, M. and Mooney, H.M. (1960) The Electrochemical Mechanism of Sulphide Self-Potential. Geophysics, 25, 226-249. https://doi.org/10.1190/1.1438689

[11] Corry, C.E. (1985) Spontaneous Polarization Associated with Porphyry Sulphide Mineralization. Geophysics, 50, 1020-1034. https://doi.org/10.1190/1.1441967

[12] Rao, M.B.R. (1953) Self-Potential Anomalies Due to Subsurface Water Flow at Gerimenapenta, Madras State, India. Transactions of the American Institute of Mineralogy, Metallurgy, Petroleum Engineering and Mining Engineering, 400-403.

[13] Schiavone, D. and Quarto, R. (1984) Self-Potential Prospecting in the Study of Water Movements. Geoexploration, 22, 47-58.

https://doi.org/10.1016/0016-7142(84)90005-X

[14] Corwin, R.F. and Hoover, D.B. (1979) The Self-Potential Method in Geothermal Exploration. Geophysics, 44, 226-245. https://doi.org/10.1190/1.1440964 
[15] Fitterman, D.V. and Corwin, R.F. (1982) Inversion of Self-Potential Data from the Cerro Prieto Geothermal Field, Mexico. Geophysics, 47, 938-945. https://doi.org/10.1190/1.1441361

[16] Ercan, A., Drahor, M. and Atasoy, E. (1986) Natural Polarization Studies at Balcova Geothermal Field. Geophysical Prospecting, 34, 475-491. https://doi.org/10.1111/j.1365-2478.1986.tb00477.x

[17] Wynn, J.C. and Sherwood, S.I. (1984) The Self-Potential (SP) Method: An Inexpensive Reconnaissance and Archaeological Mapping Tool. Journal of Field Archaeology, 11, 195-204. https://doi.org/10.1179/jfa.1984.11.2.195

[18] Drahor, M.G., Akyol, A.L. and Dilaver, N. (1996) An Application of the Self-Potential (SP) Method in Archaeogeophysical Prospection. Archaeological Prospection, 3, 141-158.

https://doi.org/10.1002/(SICI)1099-0763(199609)3:3\%3C141::AID-ARP53\%3E3.0.C O;2-I

[19] Cammarano, F., Mauriello, P., Patella, D. and Piro, S. (1997) Application of Geophysical Methods to Archaeological Prospecting. Science and Technology for Cultural Heritage, 6, 151-173.

[20] Giampaolo, V., Calabrese, D. and Rizzo, E. (2016) Transport Processes in Porous Media by Self-Potential Method. Applied and Environmental Soil Science, 2016, Article ID: 3951486. https://doi.org/10.1155/2016/3951486

[21] Roubinet, D., Linde, N., Jougnot, D. and Irving, J. (2016) Streaming Potential Modeling in Fractured Rocks: Insights into the Identification of Hydraulically Active Fractures. Geophysical Research Letters, 43, 4937-4944. https://doi.org/10.1002/2016GL068669

[22] Ram Babu, H.V. and Atchuta, D. (1988) A Rapid Graphical Method for the Interpretation of the Self-Potential Anomaly over a Two-Dimensional Inclined Sheet of Finite Depth Extent. Geophysics, 5, 1126-1128. https://doi.org/10.1190/1.1442551 